\title{
REPÚBLICA, RELIGIÓN Y LIBERTAD: LA IGLESIA Y EL FRENTE POPULAR'
}

\author{
Republic, religion and freedom: \\ The Church and the Popular Front
}

\author{
SANTIAGO NAVARRO DE LA FUENTE \\ Universidad de Sevilla \\ snav@us.es
}

Cómo citar/Citation

Navarro de la Fuente, S. (2019).

República, religión y libertad: la Iglesia y el Frente Popular.

Historia y Política, 41, 123-151.

doi: https://doi.org/10.18042/hp.41.05

(Recepción: 03/05/2018; Evaluación: 04/07/2018; Aceptación: 01/12/2018; Publicación: 13/05/2019)

\section{Resumen}

Tras la victoria del Frente Popular en febrero de 1936, la Iglesia debió asumir el fracaso de su intento de reformar la Constitución española y aquellas leyes que le resultaban más perjudiciales. Se materializaron entonces nuevos retos y peligros que amenazaban su posición. Nuestro análisis pretende abarcar el modo en que la Santa Sede trató de posicionar a la Iglesia en la Espańa de aquella nueva etapa. Para ello hemos usado las fuentes archivísticas vaticanas y el fondo de la Embajada española ante la Santa Sede con el propósito de estudiar detenidamente los meses que mediaron entre las elecciones de febrero y el golpe militar de julio de 1936. Su análisis nos ha revelado una posición lo suficientemente ponderada del Gobierno central de la Iglesia respecto de las grandes cuestiones que se planteaban en el país en aquellos meses que contrasta con algunas interpretaciones tradicionales. Junto a las protestas

1 Este artículo se enmarca en el Proyecto I+D+I HAR2015-65115-P (MINECO/ FEDER). 
por los ataques sufridos y los deseos de modificación de las normas que le resultaban más hostiles, la Santa Sede intentó acercar posturas en materia social con los elementos más moderados de la izquierda rehusando de la actitud de la CEDA en este aspecto. La defensa de sus intereses también la hizo apelar a los derechos que le reconocía la legislación, en un primer gesto de adaptación a los procedimientos democráticos.

\title{
Palabras clave
}

Iglesia; Frente Popular; Segunda República; Santa Sede; España.

\begin{abstract}
After the victory of the Popular Front in February 1936, the Church needed to accept its failure to get the Spanish Constitution and all harmful laws amended. A new threatening period of time full of risk had risen. This paper analyzes how the Holy See managed the position of the Church in Spain during that period. The study of the diplomatic documents between Spain and the Holy See revealed a balanced position of the central government of the Church about the main issues debated in Spain, which may differ from some traditional beliefs. Beside protesting the attacks received and claiming the amendment of those hostile laws, the Holy See wanted to get closer to the moderate left in social politics, rejecting the CEDA position in this sense. In search of guarding its interest, the Church was claiming their legitimate rights and this would be an evidence of its adaptation to the democratic procedures.
\end{abstract}

\section{Keywords}

Church; Popular Front; Second Republic; Holy See; Spain. 
I. INTRODUCCIÓN. II. LA PRUEBA DEL POSIBILISMO. III. EL NUEVO GOBIERNO: LOS REPUBLICANOS EN EL PODER, LOS REVOLUCIONARIOS EN LA CALLE. IV. ASPIRACIÓN Y PRÁCTICA DE UNA «POLÍTICA DE MITIGACIÓN». V. CONCLUSIONES. BIBLIOGRAFÍA.

\section{INTRODUCCIÓN}

El relato histórico de la cuestión religiosa durante la Segunda República ha encontrado tradicionalmente un punto de quiebra a partir de las elecciones de febrero de 1936. A partir de entonces, la reactivación de las medidas anticlericales y - especialmente- la violencia política que afectó en gran medida a la Iglesia han capitalizado la imagen global del periodo. Sin embargo, la investigación de las relaciones entre España y la Santa Sede durante los últimos meses de normalidad constitucional de la Segunda República, entre febrero y julio de 1936, revela distintos aspectos que pueden enriquecer esta visión clásica. De hecho, muy recientemente González Gullón y Martínez Sánchez han puesto de relieve que «apenas hay trabajos sobre la conducta del estamento eclesiástico en aquellos meses decisivos $»^{2}$.

Este artículo pretende ser una aportación en este sentido. Para ello partimos de los meses precedentes, en los que la Santa Sede comenzó a ver cada vez más improbable su pretensión de que la Constitución pudiese ser modificada y de que los católicos españoles consiguieran posponer sus querellas políticas para aglutinar una mayoría social que los llevara al Gobierno. De esta forma, el resultado de las elecciones de febrero de 1936 certificó el fin de la estrategia reformista pretendida por la Santa Sede y la condujo a un nuevo marco de relaciones con la Espańa del Frente Popular asumiendo la imposibilidad de modificar su situación legal.

La documentación vaticana disponible para consulta y los fondos documentales de la Embajada de España ante la Santa Sede permiten reconstruir con detalle la relación que desde el Gobierno romano de los católicos se intentó

2 González y Martínez (2017): 1622. Cruz (2006: 127-132) ha calificado la actividad de los católicos como la «movilización del desagravio». También dentro de estudios más completos ha tratado la cuestión Cárcel Ortí $(2008,2016)$, cuyas ediciones de la documentación vaticana son de máxima utilidad a pesar de no eximir por completo de la consulta de los originales. 
mantener con España desde entonces. La conciencia de la necesidad de una política social reformadora, el afán de sustitución o mitigación de las leyes más duras contra la Iglesia y la capacidad de esta para adecuarse a los resortes legales que podían proteger sus intereses fueron cuestiones abordadas durante el periodo junto al temor de una evolución hacia el comunismo. De su estudio puede extraerse una imagen más ponderada sobre el papel del Gobierno central de la Iglesia respecto de la España de los años treinta que, además, permite completar nuestros conocimientos sobre la cuestión religiosa a lo largo del periodo republicano.

\section{LA PRUEBA DEL POSIBILISMO}

La entrada de la CEDA en el Gobierno en octubre de 1934, más allá de la magnitud de la insurrección con que las izquierdas revolucionarias reaccionaron a la participación de los posibilistas en el Ejecutivo, supuso la puesta en práctica de un proyecto político en el que habían convergido muy distintos acentos y que debió entonces concretarse en la acción de gobierno. La Santa Sede había insistido desde tiempo atrás en la urgencia con que los católicos españoles debían dedicarse a una acción social más amplia ${ }^{3}$. La llegada de Manuel Giménez Fernández al Ministerio de Agricultura supuso un gran avance en este sentido. Sin embargo, sus orientaciones trajeron también un quebradero de cabeza para Gil Robles puesto que atentaban contra los intereses de importantes propietarios que también se integraban en el partido. El líder salmantino había usado una cierta ambigüedad en el discurso para sumar los más apoyos posibles a la Coalición de Derechas Autónomas, consiguiendo integrar en una única formación a sinceros católicos junto con otros perfiles conservadores menos movilizados desde el punto de vista religioso. Cuando Manuel Giménez Fernández accedió a la cartera de Agricultura lo hizo con la pretensión de corregir la orientación de la reforma agraria del primer bienio en un sentido socialcristiano. El Debate llegó a comparar sus proyectos con "encíclicas hechas leyes», pero el ministro topó en su gestión con la oposición firme de algunos de sus correligionarios, que le llamaron «bolchevique blanco» o "marxista disfrazado» a causa de sus intenciones. Entre ellas estaba no solo mantener la Ley de Reforma Agraria del primer bienio, sino que preveía asentar unos diez mil colonos nuevos en las tierras que habían de expropiarse a lo largo de 1935. Finalmente, y a pesar del apoyo con que el ministro contaba entre los jóvenes del

3 Rodríguez Lago (2017): 246. 
partido, Gil Robles resolvió prescindir de él en el ministerio y fue sustituido en abril de ese añó ${ }^{4}$.

La lectura que de ello hicieron en la Santa Sede fue transmitida a Espańa por el embajador Pita Romero. El 9 de julio de 1935, a partir de un artículo publicado en L'Avvenire d'Italia, diario de la Acción Católica Italiana, Pita informó al Gobierno de lo que consideraba una advertencia de la Santa Sede en toda regla sobre la «necesidad de que los partidos católicos hicieran política en favor de una distribución más equitativa de la riqueza». El embajador entendía que en aquel momento el diario era la voz que el Vaticano no tenía la libertad de levantar desde L'Osservatore romano, y añadió en el telegrama que informaba de la remisión del texto: "Combate actitud conservadora católicos apegados particulares intereses y elógiase actitud Jimenez Fernández advirtiendo peligro que por desilusión masas ante desatención estos problemas o realización política defensora privilegios apoyen partidos izquierda próximas elecciones. Afirma que problema principal España es social y por incapacidad resolverlo cayó monarquía»"

La Santa Sede insistía en la necesidad de recuperar a las masas de obreros que habían optado por las promesas revolucionarias en lugar de las soluciones cristianas; $y$ en el peligro que estas se mostrasen ineficaces o - peor aúninexistentes. Por ello apelaba a la orientación socialcristiana que en origen se había proyectado sobre Acción Popular, con el propósito de que esta no dejara de ser fiel a su programa de cumplimiento de la doctrina social de las encíclicas pontificias. Sin embargo, esta orientación moral de la política se enfrentaba a los límites que la propia dimensión práctica de las cosas imponía y que en este caso pasaba por la pérdida de apoyos cuando no por el enfrentamiento abierto en las propias filas de la CEDA.

Si la actitud de los católicos respecto de la cuestión social era una preocupación de largo recorrido en la actitud vaticana de entreguerras, la revisión constitucional era el principal objetivo para acomodar a la Iglesia en una República de la que había dispuesto acatamiento, pero cuyas leyes en materia religiosa le habían resultado muy perjudiciales. De hecho, la Santa Sede había interrumpido en marzo de 1935 la negociación de un modus vivendi que no

4 Macarro Vera (2000): 377-379; Álvarez Rey (2005): 213-215, y Álvarez Tardío (2016): 163-167.

5 Telegrama núm. 64 enviado por el embajador ante la Santa Sede, Leandro Pita Romero, al Ministerio de Estado el 9 de julio de 1935. Archivo de la Embajada de España ante la Santa Sede (en adelante AEESS), serie 1901-1948, legajo 56. El telegrama se refiere al artículo "Le Destre spagnole e la giustizia sociale» publicado por el diario L'Avvenire d'Italia ese mismo día. 
quería inscribir en el marco de una norma fundamental que no podía entonces modificarse ni había garantía cierta de que se hiciese en el futuro ${ }^{6}$.

En el mes de julio de 1935 el presidente del Gobierno, Lerroux, leyó en Cortes un primer proyecto que afectaba a cuarenta artículos. Gil Robles apoyó aquel principio de acuerdo que afectaba al art. 26, pero manteniendo la aconfesionalidad prevista en el art. 3, y eliminaba el veto a que los religiosos pudiesen ejercer la enseñanza. Sin embargo, la modificación no era viable hasta que en diciembre pudiese tramitarse con la mayoría absoluta de la Cámara en lugar de la mayoría reforzada vigente todavía en julio. Por otro lado, la modificación de la Carta Magna conllevaría inevitablemente la disolución de las Cortes y la convocatoria de nuevas elecciones, por lo que parecía más lógico a la mayoría cedista aplazar la reforma hasta el final de la legislatura, máxime si el desarrollo de esta podía posibilitar el encargo del Gobierno al propio Gil Robles.

La modificación constitucional, sin embargo, estaba llamada a enfrentar a la CEDA con parte de su electorado en función de la profundidad con la que se procediera. Si se producía solo en aquellos extremos en que afectaba a los derechos de la Iglesia, pero sin discutir la cuestión de régimen, los monárquicos acusarían a los posibilistas de consolidar la República y tratarían de atraerse a los más afines a su causa de cuantos se integraban en la formación de Gil Robles; y si se pretendía una reforma integral — como así llegó a asegurar el político salmantino a comienzos de septiembre de 1935- que afectase incluso a la cuestión de régimen, conllevaría el abandono del posibilismo en favor de una confrontación mucho más abierta con el modelo republicano perjudicando sus apoyos más moderados?.

Para el 30 de octubre de aquel mismo ańo, coincidiendo con la salida del Gobierno del líder republicano radical Alejandro Lerroux — que ocupaba la cartera de Estado- y la formación de un nuevo Ejecutivo en cuya presidencia repetía Joaquín Chapaprieta, Pita Romero volvió a enviar a Madrid los puntos de reflexión de L'Avvenire d'Italia sobre la situación política en España. Preocupaba entonces en Roma que Unión Republicana se creciera con los diputados que abandonaran el Partido Radical y que ello, unido a los escándalos de corrupción de los radicales, provocase la disolución de las Cortes y la convocatoria de elecciones. En tal circunstancia, entendían que la reforma de la Constitución quedaría aplazada sine die y

Redondo Torres (1993): 424-439, y Batllori y Arbeloa (1990): documento 1134.

Álvarez Tardío (2016): 194-196. El nuncio Tedeschini informó el 12 de septiembre de 1935 acerca de las declaraciones de Gil Robles en defensa de una "Costituzione nuova». Cárcel Ortí (2016): documento 1526. 
que las elecciones no serían favorables a las derechas. La preocupación por la reforma constitucional llevaba a la Santa Sede a una llamada a los monárquicos para deponer sus principios políticos en aras de la modificación y de una normalización republicana que resultase más cómoda a la Iglesia. Era una apelación plena de candidez religiosa, aunque con cierta ingenuidad política: la que suponía intentar atraer hacia la consolidación de la República a quienes tenían por principio combatirla ${ }^{8}$.

La crisis de los radicales y la negativa de Alcalá Zamora a llamar al Gobierno a Gil Robles llevaron finalmente a la disolución de las Cortes y la convocatoria de elecciones. El 15 de enero de 1936 el nuncio Tedeschini envió a la Secretaría de Estado un despacho en el que analizaba la disolución del Parlamento y la situación a la que había llevado aquella disposición del presidente. Advertía, en primer lugar, que «non è del tutto vero» que las Cortes del segundo bienio no tuviesen un funcionamiento normal, tal y como había argüido Alcalá Zamora al disolverlas. El nuncio explicaba que, a pesar de la crisis de los de Lerroux, las Cortes podían funcionar normalmente porque existía un partido que podía asumir el poder y reunir en torno a sí la mayoría: la CEDA. Era lo que Tedeschini consideraba la única salida constitucional posible para aquella situación, pero a lo que Alcalá Zamora se había opuesto por su abierta discordia con Gil Robles. Esta oposición le había llevado a formar un gabinete sin base parlamentaria y a disolver las Cortes aun a riesgo de que la nueva Cámara decidiese sobre su propia destitución. El análisis de aquella peculiar situación de la República llevó a Tedeschini a reflexionar sobre las dificultades que todo ello representaba al propio sistema y la ventaja que podían obtener los monárquicos. El nuncio argumentó que, al igual que en 1931 la monarquía había caído no tanto por el éxito de los republicanos sino por los errores de los monárquicos, entonces eran los propios partidarios del nuevo régimen los que lo estaban poniendo en peligro?.

Este comentario que el nuncio enviaba al cardenal secretario de Estado, Eugenio Pacelli, ponía de relieve las limitaciones para la apelación pontificia a la unidad de los católicos españoles. Por aquellos días el cardenal Gomá, que regresaba de Roma, donde le había sido impuesta la birreta cardenalicia, recordaba a los católicos el deseo de Pio XI de que postergasen sus querellas políticas para garantizar con su unidad política la salvaguarda de los principios más fundamentales. De esta unidad dependía la corrección de las medidas antirreligiosas del ordenamiento vigente, en primer término, y la evitación de la revolución proletaria de las izquierdas más radicales, en última instancia.

8 AEESS, despacho de 30 de octubre de 1935. Tomado de la Serie 1901-1948, legajo 56.

9 Cárcel Ortí (2016): documento 1557. 
Esta enésima invitación a la unidad tuvo el mismo eco que sus predecesoras. Durante la campaña, los monárquicos de Renovación Española liderados por Calvo Sotelo fueron muy duros contra Gil Robles y ejemplificaron en la disolución de las Cortes el fracaso de la estrategia cedista. La presentaron como víctima de la ilusión de corregir una República que ellos creían en sí misma un mal a evitar. Acusaron, además, al líder posibilista de falta de rigor y de habilidad política para solucionar los males del país. Y frente a las llamadas de los obispos a la unidad, Calvo Sotelo recordó que ellos eran «sinceramente católicos» y que no podía consentirse que ningún partido monopolizara el catolicismo. «La jerarquía eclesiástica — dijo- no puede convertirse en una oficina electoral». Para ellos, la aspiración era la modificación del propio modelo del Estado ${ }^{10}$.

El informe del nuncio de 15 de enero de 1936 terminaba con una lectura muy concreta de la trascendencia de la elección convocada para el 16 de febrero. Si la victoria era de las derechas, Tedeschini consideraba que se procedería no ya a la reforma de la Constitución, sino a la elaboración de una nueva. Por el contrario, si ganaban las izquierdas, el resultado sería la revolución y la dictadura del proletariado ${ }^{11}$. En este sentido, aunque unos días después el nuncio envió a Roma el manifiesto electoral del bloque de izquierdas valorando su tono moderado, en el que no se hacía afirmación alguna sobre la cuestión religiosa, advertía que la mesura del manifiesto bien podía resultar una estrategia para alcanzar el poder, y una vez tomado las circunstancias serían muy otras. Especialmente porque los hombres que se proponían llevar a efecto el programa de las izquierdas no eran «uomini di mezze misure» ${ }^{12}$.

\section{EL NUEVO GOBIERNO: LOS REPUBLICANOS EN EL PODER, LOS REVOLUCIONARIOS EN LA CALLE}

Las horas que mediaron entre el cierre de los colegios el día 16 de febrero y la formación del nuevo Gobierno presidido por Manuel Azańa resultaron decisivas $^{13}$. De lo sucedido entonces dio cumplida cuenta Tedeschini en un

$10 \quad$ Navarro de la Fuente (2017): 1665.

11 Álvarez y Villa (2017: 76) indican que las fuerzas obreras habían concurrido a las elecciones con unos propósitos que no pasaban ya por «el constitucionalismo ni el sistema parlamentario», sino que aspiraban a la «dictadura del proletariado».

12 Cárcel Ortí (2016): documentos 1557 y 1560.

13 Álvarez y Villa (2017): 275-351. 
extenso rapporto de 22 de febrero de $1936^{14}$. El ya cardenal iniciaba su informe recordando la perspectiva de victoria con la que las derechas concurrían a aquellos comicios y aportando algunos datos sobre el número de escaños que preveían obtener cada uno de los partidos. En la sera de la propia jornada electoral la sensación de victoria de las derechas cambió por el desaliento y este por "pánico" a la violencia con la que las izquierdas podrían celebrar la victoria: «Due giorni di piena e assoluta licenza per darsi a quanti eccessi avessero voluti». Una violencia que esta vez temía el nuncio que se dirigiese no solo a los edificios, sino también contra las personas, tal y como decía haber advertido Largo Caballero, «il Lenin spagnuolo».

El jueves 20 de febrero, a las pocas horas de la formación del gabinete presidido por Azaña, el miedo aumentó y el nuncio refirió cómo el obispo de Madrid, Leopoldo Eijo y Garay, había sido advertido por el dominico padre Gafo y por el cedista Cándido Casanueva del inminente incendio de conventos. La advertencia llevó al prelado a indicar a los religiosos que salieran de sus cenobios y se refugiaran en casas particulares. Sin embargo, en la capital no ocurrió nada, mientras que fue en otras zonas del país donde fueron asaltadas las iglesias. Azaña y el nuevo ministro de Estado, Augusto Barcia, adujeron que se trataba de actos provocados por alborotadores que aprovechaban el vacío de autoridad del tránsito de un Gobierno al siguiente. Frente a ello, el nuevo presidente del Ejecutivo defendió en público desde la sede del Ministerio de la Gobernación la defensa del orden, comprometiéndose a garantizarlo. El nuncio quedó a la espera de comprobar si era o no cierta aquella proclama.

El informe continuaba llamando la atención sobre la evolución de los datos de escrutinio que se iban conociendo. Si en las primeras horas de recuento los datos otorgaban una buena posición a las derechas a pesar de la derrota, la situación cambió en los días siguientes. Tedeschini, que había considerado la posibilidad de que la unión de las izquierdas se resquebrajara con la escisión de algunos de sus integrantes a lo largo de la legislatura, dudaba de la limpieza de los resultados que se iban conociendo hacia el 22 de febrero ${ }^{15}$.

$\mathrm{Al}$ respecto del escrutinio, parece claro que las elecciones del 16 de febrero se celebraron con toda limpieza. Sin embargo, la «huida» del Gobierno de Portela y la rápida sustitución de los gobernadores civiles y otras autoridades mucho antes de que se culminaran las garantías electorales que debían tener lugar después de la votación pudo estar detrás de esta variación de

14 El martes 18 de febrero, mediante telegrama, Tedeschini dio noticia de la victoria de las izquierdas aun a pesar de que la CEDA había conseguido mejorar su número de escaños en el Congreso. Cárcel Ortí (2016): documento 1571.

15 Cárcel Ortí (2016): documento 1571. 
escaños que llamó la atención de Tedeschini ${ }^{16}$. En sus memorias, Alcalá Zamora explicó: «La dimisión-huida de Portela, arrastrando consigo el terror de los ministros, se tradujo en muchas provincias en fuga escandalosa de los gobernadores, y de los gobiernos civiles encargáronse, en sustitución tumultuaria y anárquica, en varias provincias, subalternos y aun del todo indocumentados $»^{17}$.

Tedeschini continuó su análisis de la situación advirtiendo de la ausencia de los socialistas en el Gobierno y sospechando que se debía a la profundización de Largo Caballero en la aspiración de que la revolución desbordase a una República que, no obstante, prefería en manos de las izquierdas. El nuevo Gobierno había repuesto los ayuntamientos elegidos en abril de 1931 a la espera de la convocatoria de nuevas elecciones, así como sustituido los gobernadores civiles. A ello se unía la aprobación de la amnistía para los encarcelados por la revolución de octubre de 1934 — con el apoyo de la Diputación Permanente de las Cortes ya disueltas - y la aspiración a la inmediata sustitución de la enseñanza en centros religiosos en desarrollo del art. 26 de la Constitución.

Tedeschini también tuvo unas líneas para destacar el aumento del número de votos de las derechas respecto de las elecciones de noviembre de 1933. Lo atribuía a que el hundimiento de los radicales había enviado dos tercios de los votos perdidos al Frente Popular y el último a las alianzas de derecha. El nuncio terminaba su análisis aludiendo a la aprobación de la amnistía por la Diputación Permanente de las Cortes incluyendo el concurso en ello de las derechas; lo que juzgaba un gesto de "pace, di indulgenza e di benevolenza». A ello añadía las apaciguadoras palabras de Azaña y la esperanza de que las izquierdas buscaran la moderación.

El cambio de Gobierno tuvo como consecuencia la dimisión del embajador de España ante la Santa Sede, Pita Romero. El que había sido el primer representante de la República ante el papa, que había regresado a España para las elecciones, volvió a Roma para cerrar todos los asuntos concernientes a su marcha y despedirse de las autoridades vaticanas. El día 7 de marzo se entrevistó con Pacelli y también con dos de los hombres capitales de la Secretaría de Estado del momento: el secretario de la Sagrada Congregación de Asuntos Eclesiásticos Extraordinarios, Giuseppe Pizzardo, y el sustituto de la propia secretaría, Domenico Tardini ${ }^{18}$. De aquel encuentro, Pita Romero escribió:

\footnotetext{
Álvarez y Villa (2017): 409.

Alcalá Zamora (1998): 394.

18 Pizzardo era, además de secretario de Asuntos Extraordinarios, el responsable internacional para la Acción Católica. De Domenico Tardini es significativa la alusión
} 
Deduje de las conversaciones con los tres citados dignatarios que creen que se entra en un periodo de inactividad diplomática entre Espańa y la Santa Sede, y que tienen una actitud de expectación benévola respecto a posibles acercamientos e inteligencias con elementos de derecha. Creo que el Vaticano se felicitaría de que en España evolucionasen los partidos en el sentido de que la derecha fuese menos derecha y la izquierda menos izquierda, y liberasen de las influencias intransigentes que sobre cada uno pesan ${ }^{19}$.

El comentario, de un idealismo que si no tuviera en cuenta las personalidades a que se refería parecería casi ingenuidad, situaba a la Secretaría de Estado en línea con el propósito de Alcalá Zamora de hacer emerger un centro político que se alejara de los extremos. Es razonable pensar que no era esta la postura, sino que la Secretaría de Estado no dejaba de insistir en la aplicación de una serie de medidas sociales orientadas a la satisfacción de las demandas obreras, pero desde posiciones católicas. En tal sentido, se inclinaba a defender las medidas sociales de las izquierdas, pero aplicando la política religiosa y moral de las derechas. Esta intención, más que con el centro político deseado por el presidente de la República se situaba en relación con los primeros datos del escrutinio electoral que dibujaba una victoria del Frente Popular, pero una oposición derechista muy crecida, con unos muy buenos resultados electorales para la CEDA. De este modo, y aspirando a que la coalición de izquierdas pudiese resquebrajarse a lo largo de la vida de las Cortes que estaban por constituirse, parecía deseable a los eclesiásticos que los republicanos de izquierda necesitasen de apoyos a su derecha para mantener el poder y así pudiese llegarse a esta política de izquierdas en lo social y de derechas en lo moral y religioso. Sin embargo, la merma de escaños de las derechas a medida que se completaba el escrutinio y la posterior discusión de las actas alejaron esta posibilidad que, además, gravitaba en una percepción de Azaña como un político mucho más moderado de lo que sus preferencias en las alianzas evidenciaban. El modo en que el informe de Pita continuaba profundizaba en esta línea, ya que refería el «examen de conciencia» de los eclesiásticos sobre la actuación de sus correligionarios en España a la vez que trataba de dar forma a aquel nuevo anhelo: «Creo que la Secretaría de Estado no está satisfecha de la actuación de los partidos católicos en el Gobierno en materia social, y que la juzgan excesivamente conservadora y condición del triunfo electoral de las izquierdas. En la conversación con Mons. Pizzardo advertí

que hace Raguer (2001: 46) a su expresión de «benedetta rivoluzione» para calificar la Segunda República en tanto que le daba la bienvenida al cese de las peculiares relaciones entra la depuesta monarquía y la Iglesia.

19 Despacho núm. 77 de 7 de marzo. AEESS, despachos encuadernados, 1936. 
claramente que propugnaría todos los apoyos al Gobierno en materia de reformas sociales, si no tomase iniciativas que perjudicasen la cuestión religiosa ${ }^{20}$.

Sin duda, la llamada de Azaña a la concordia en las horas siguientes a hacerse cargo del Gobierno había calado en la Secretaría de Estado, hasta el punto de situarla en el deseo de sostenerle en el Gobierno a cambio de determinadas contrapartidas ${ }^{21}$.

El primer contacto de Tedeschini con el nuevo ministro de Estado, Augusto Barcia, estuvo marcado por el descubrimiento de un depósito de armas en una iglesia de Barcelona en la tarde del 20 de febrero. Barcia se lo comunicó al nuncio por teléfono justo después de la visita de cortesía que había efectuado a la Nunciatura en la jornada siguiente a la formación del Gobierno. El cardenal efectuó las oportunas gestiones para informarse de lo sucedido hasta el punto de que el sábado 22 de febrero recibió en Madrid al obispo de Barcelona, Manuel Irurita. Este le explicó que el coronel Becerra, de la Guardia Civil, viendo a las fuerzas que comandaba incapaces de controlar los múltiples asaltos a las iglesias, había previsto que los párrocos designasen personas de confianza para defenderlas. A cada uno de ellos debía entregársele un arma y una cédula con la licencia para portarla. Todo ello — afirmó el obispo-con el oportuno permiso del gobernador general de Cataluña, Carlos Esplá, y del propio Portela Valladares. En el último momento, las mil quinientas cédulas que se requerían no pudieron ser firmadas, pero ello no fue óbice para que cuando los asaltantes se presentaron en una de las parroquias fuesen rápidamente disueltos por los voluntarios. En las informaciones que Tedeschini dio sobre lo sucedido al ministro Barcia, lejos de lamentar la gravedad de una situación en que la fuerza pública requería del apoyo de civiles armados para detener los asaltos, con el consecuente peligro de que quienes recibían las armas terminasen por convertirse en nuevos asaltantes aunque de signo opuesto ${ }^{22}$, el nuncio recomendó al ministro que mantuviera la premura en informarle de cualquier cuestión que afectase a personas eclesiásticas y le animó a reproducir la estrategia seguida en Barcelona. Así, ya el 23 de febrero, el representante del

20 Id.

21 Ángel de la Mora, encargado de negocios de la Embajada ante la Santa Sede, en su despacho de 26 de febrero indicó que «a partir de la proclama del Excmo. Señor Presidente del Consejo de Ministros, Don Manuel Azaña, llamando a todos los españoles a la concordia, había mayor optimismo en los centros vaticanistas». Despacho núm. 66 de 26 de febrero. AEESS, despachos encuadernados, 1936.

22 Cuando Tedeschini requirió información de lo sucedido al cardenal Vidal y Barraquer, este aludió a la fervorosa militancia tradicionalista del secretario de Cámara y Gobierno del obispo de Barcelona. 
papa en España indicó a Barcia que si el Gobierno no contaba con fuerza suficiente para detener los ataques a las iglesias, la Iglesia misma podría organizarse para hacerlo y «sarebbe felice di vedere poste agli ordini del Governo». El eclesiástico insistía en el carácter disuasorio de aquella suerte de milicias parroquiales que en ningún caso debían hacer fuego ${ }^{23}$.

La disuasión de los asaltantes no fue, desde luego, la tónica general de lo que ocurrió con la Iglesia durante la primavera de 1936. Se produjo entonces una «iconoclastia de masas» en la que se ha visto la pretensión de implantar «un nuevo estado de cosas social, económico y político, a costa del sacrificio, casi siempre traumático, de los antiguos modelos de institucionalización religiosa del orden societario ${ }^{24}$. Por su parte, María Thomas ha interpretado que esta fue la forma en que las masas de "trabajadores anticlericales» reaccionaron ante la ineficacia de las medidas legislativas secularizadoras y por ello trataron de «imponer sus propias soluciones ${ }^{25}$. Los datos sobre el modo en que la Iglesia fue damnificada por los diferentes asaltos sufridos entonces han sido bien estudiados. González Calleja ha considerado que este fue «el periodo iconoclasta más intenso de la República», señalando que en el mes de junio y principios de julio se constató una «sensible disminución de los incidentes» que provocó un grave deterioro a 153 establecimientos $^{26}$. Por su parte, Álvarez Tardío y Villa García han cifrado en 957 ataques de violencia anticlerical los perpetrados en Espańa durante los 121 días que mediaron entre el 17 de febrero y el 16 de junio de $1936^{27}$. Aun siendo los datos muy llamativos, aún más lo resulta la actitud que las autoridades mantuvieron. Estos autores han señalado que "especialmente en aquellas poblaciones donde la violencia alcanzó mayores proporciones, la reacción de las autoridades fue como mínimo tímida", aunque matizando que "no se puede concluir que, de forma generalizada, las fuerzas de seguridad no actuaran o lo hicieran tarde». La respuesta dependió de diversos factores como la voluntad del respectivo gobernador civil, con independencia de la mayor o menor tibieza del responsable del Ministerio de Gobernación en cada momento ${ }^{28}$.

La violencia que azotaba las calles del país tuvo su eco en las relaciones entre la Santa Sede y el Gobierno español. Cuando el 18 de marzo de 1936 tuvo lugar la audiencia de despedida del embajador Pita Romero ante Pío XI,

\footnotetext{
Cárcel Ortí (2016): documento 1573.

Delgado Ruiz (2001): 77.

Thomas (2014): 71.

González Calleja (2014): 269-270. Toma los datos de Ranzato (2011): 214-232.

Álvarez y Villa (2013).

Ibid.: 713-714 y 716 .
} 
el Papa transmitió un profundo pesimismo sobre la situación mundial de aquella hora a lo largo de un encuentro que se prolongó más de lo habitual. Esa mañana se había difundido la noticia en Italia de que en Jumilla se había linchado a dos presos puestos en libertad, cuyas cabezas habían sido paseadas por la población clavadas en sendas picas. El embajador quitó peso a la información, que presentó como un acontecimiento aislado. No era ese el criterio del papa, que veía en la situación en España una «muestra más del progreso de la revolución en el mundo", que ilustró evocando sus recuerdos como representante pontificio en la Polonia de la guerra contra los soviéticos. Respecto a las elecciones, la conversación de despedida dejó ver que la intención del papa de que los católicos españoles se uniesen en torno a la defensa de la familia, el modelo de enseñanza y los derechos de la Iglesia, así como las orientaciones para que la Acción Católica se abstuviera de toda política partidista, no habían cosechado gran éxito ${ }^{29}$. El 30 de marzo de 1936 el Palacio de España fue entregado a Ángel de la Mora, quien quedó como encargado de Negocios hasta la llegada de Luis de Zulueta.

También a finales de marzo, el día 27, y después de haber enviado al Gobierno a mitad de mes una nota de protesta por los ataques que estaban sufriendo las iglesias en España, Tedeschini trató sobre la grave situación en el país mediante despacho a la Secretaría de Estado. El nuncio fue tajante en aquel informe: «Il comunismo ha fatto veramente la sua apparizione, in forma terrorizzante». Desde la celebración de las elecciones, los partidos extremistas y en particular socialistas y comunistas - cuyas juventudes habían sido unificadas- habían aprovechado toda ocasión para dar rienda suelta a sus "più brutali odii politici». La furia de los ataques no se dirigía solo contra lo eclesiástico, sino que afectaba igualmente a los edificios y símbolos de las derechas. Es destacable que Tedeschini insistiese en este aspecto, aun cuando advertía que no podía dar relación de los ataques sufridos por los partidos políticos a diferencia de lo que hacía con los habidos contra la Iglesia ${ }^{30}$. Y todo ello, proseguía la información, «non solo sotto gli occhi dell'autorità, ma colla presenza e quindi coll'approvazione di essa». A juicio del nuncio, el Gobierno «non avesse forza o non avesse volontà» para la salvaguarda del orden. La situación, siendo grave en la capital, lo era aún más en las poblaciones pequeñas donde se había dado rienda suelta a toda clase de venganzas y rencillas personales. A resulta de todo ello — juzgaba Tedeschini- las clases acomodadas que pretendían desde

29 Despacho núm. 80 de Pita Romero al Ministerio de Estado, de 20 de marzo. AEESS, despachos encuadernados, 1936.

30 De la Cueva Merino (1998: 258) también señaló la vinculación de estos ataques con la violencia política. 
antiguo el descrédito de la República se afanaban en la propaganda coadyuvando a crear un estado de alarma y pánicos permanentes ${ }^{31}$.

En aquel ambiente, los rumores sobre el advenimiento definitivo de la revolución se multiplicaban y cada uno proponía una fecha para el momento. En este contexto, el nuncio señalaba lo simbólico que podría resultar el momento inmediatamente siguiente a las elecciones municipales que estaban convocadas para el 12 de abril. Del mismo modo que la elección de munícipes cinco años antes había servido para la proclamación de la República, la clamorosa victoria a la que aspiraban las izquierdas en las nuevas elecciones municipales podría convertirse en la película de legitimidad necesaria para la instauración —en términos de Tedeschini- del comunismo. El informe aludía también a la huida a la frontera de muchos que temían la evolución desfavorable de la situación y situaba como remedio a aquella deriva la intervención del ejército. Finalmente, informaba de las precauciones tomadas por algunas congregaciones religiosas y algunos curas ante lo que consideraba una "persecuzione» que incluso había dejado «veri martiri».

Las elecciones municipales fueron finalmente suspendidas. El nuncio informó de ello el 6 de abril, dando cuenta también de un discurso de Azaña en que trataba de llamar a la calma garantizando el cumplimento del programa del Frente Popular sin que se quitase ni añadiese nada y calificando como "patrańa» tanto la creencia del advenimiento del comunismo como de la solución militar a la que aludía sin nombrarla. Tedeschini, sin embargo, no daba demasiada credibilidad a sus llamadas a la calma y a la confianza, puesto que a su llegada al poder también había prometido «ordine e pace, ma non abbiamo avuto né ordine né pace» ${ }^{32}$.

El 24 de abril, mientras en la Embajada ante la Santa Sede se esperaba la llegada del nuevo titular, L'Osservatore Romano trató sobre España en su Acta Diurna. El Vaticano se hacía eco de que la situación en el país podía considerarse previa a la revolución proletaria. El autor del comentario era el político italiano Guido Gonella, que escribió bajo el título «Mosca saluta i 'fratelli' spagnoli» ${ }^{33}$. El encargado de Negocios, De la Mora, sintetizaba la opinión de Gonella en los siguientes términos:

Refiriéndose concretamente al caso de España dice que en la política de Moscú se pueden distinguir tres momentos: $10^{\circ}$ Moderación preelectoral para no alarmar a los elementos burgueses de izquierda. 2..$^{\circ}$ Entrega del poder a las fuerzas

31 Cárcel Ortí (2016): documento 1591.

32 Cárcel Ortí (2016): documento 1596.

33 L'Osservatore romano de 24-4-1936. 
burguesas, para que asuman estas la responsabilidad de disgregar los organismos sociales. Y 3. ${ }^{\circ} \mathrm{El}$ momento de la realización revolucionaria» que toma pretesto [sic] en el desorden... preordenado ${ }^{34}$.

De la Mora no se atrevió a ir más allá en su comentario. Tampoco se trataba de un editorial, aunque no dejaba de ser una columna en el medio oficioso vaticano. En el mejor de los casos se trataba de una advertencia de que la situación creada en España encajaba demasiado bien con las etapas que refería Gonella y con la estrategia que socialistas y comunistas habían manifestado durante la campańa electoral en relación al manifiesto de su propio bloque. El socialista Álvarez del Vayo había afirmado entonces que el pacto solo podría ser eficaz si después de las elecciones se mantenía «la presión popular». Los comunistas también habían coincidido en que, más allá de la acción parlamentaria y legislativa, «las masas antifascistas» debían proceder a la realización del pacto «en la calle». Concebían así la victoria del Frente Popular como una etapa transitoria hasta la "dictadura democrática del proletariado»" 35 . Sin embargo, el prepósito general de los jesuitas, Ledóchowski, escribió a la Secretaría de Estado vaticana el día 25 de abril — veinticuatro horas después de la publicación de Gonella en L'Osservatore - indicando que, según sus informaciones, los delegados de la Comintern enviados a España habían considerado imposible la revolución por la incapacidad de transformar el ardor destructor de las masas en una toma revolucionaria del poder que articulase el comunismo. Así, juzgaban que la celebración de elecciones municipales hubiera conllevado probablemente el desate de las pasiones y «la proclamación circunstancial del comunismo en varios miles de Ayuntamientos rurales donde se izaría la bandera roja, se quemaría la iglesia, y asesinaría al cura, a la pareja de la Guardia Civil y a los más ricos del pueblo», pero entendían que ningún dirigente socialista o comunista sería capaz de aprovechar esta coyuntura para tomar el poder ${ }^{36}$.

34 Despacho núm. 108 de 24 de abril al ministro de Estado. AEESS, despachos encuadernados, 1936.

35 Álvarez y Villa (2017): 96.

36 La carta de Ledóchowski a Pizzardo, en Cárcel Ortí (2016): documento 1608. Elorza y Bizcarrondo (1999: 281-282) refieren el envío a Manuilski el 4 de marzo de un largo informe aludiendo al «extremismo infantil» de los caballeristas y al encuadramiento de la situación española en la fase democrático-burguesa de la revolución, aunque refieren igualmente el constante crecimiento de la influencia comunista. Rees (2012: 302-304) ha explicado cómo, a pesar de que la posibilidad de que los comunistas tomasen el poder a las órdenes de la Comintern era «ridícula», aumentó el temor de los conservadores españoles. 
El 1 de mayo tomó posesión de la Embajada de Espańa ante la Santa Sede Luis de Zulueta. En ese simbólico día, el hombre que no había obtenido el plácet en 1931 pero que entonces ocupaba ya el Palacio de Espańa, fue a saludar — sin carácter oficial — a la Secretaría de Estado, donde se encontró tanto con el secretario de Asuntos Eclesiásticos Extraordinarios, Pizzardo, como con el sustituto de la Secretaría de Estado, Tardini. Según el parecer del recién estrenado embajador, la acogida que le dispensaron ambos eclesiásticos fue «francamente afectuosa». El primero de los encuentros fue con Pizzardo, con quien trató sobre el «orden público». El embajador aprovechó para «contrarrestar con mis noticias y consideraciones los informes falsos o, por los menos, parciales y adversos que aquí deben recibirse con excesiva frecuencia». Pizzardo fue basculando por los principales temas a los que le interesaba aludir. Por eso se refirió, "con carácter general, al peligro comunista y a los riesgos de los movimientos separatistas». Del encuentro, escribió Zulueta:

Por lo que toca al peligro comunista, no he negado su existencia en España pero sí que aquel fuese tan grave como algunos suponen. Estimo que no debemos negar la realidad de este peligro, entre otras razones porque solo el temor a situaciones más extremas puede llevar al Vaticano a admitir la política que encarna el Gobierno y las Cortes de la República. Traté, no obstante, de persuadir a Mons. Pizzardo de que bajo la dirección del Sr. Azaña se lograrán plenamente la normalidad, el orden y la estabilidad de la vida pública española y de que todo intento de centrarla hacia la derecha, como los realizados durante el pasado bienio, estaba condenado al fracaso y constituiría el mejor estímulo para una revolución comunista. No se ha mostrado el Secretario en desacuerdo con la conveniencia de una política 'progresiva', especialmente en el terreno social confirmándome la impresión que ya tenía, de que el Vaticano no estaba muy satisfecho de la política excesivamente conservadora, sobre todo en el aspecto económico, practicada por los católicos espańoles ${ }^{37}$.

Venía Zulueta a confirmar la percepción, que ya había transmitido su predecesor en el cargo, acerca del descontento que en la Santa Sede había provocado la actuación política de los católicos de la CEDA en materia social durante el segundo bienio republicano. Y a fijar una posición que no estaba lejos de la que anhelaban en la Secretaría de Estado a pocas horas de las elecciones, salvo un matiz importante: Zulueta presentaba a Azańa —o al hombre

37 Despacho núm. 114, del embajador Luis de Zulueta al ministro de Estado de 1 de mayo. AEESS, despachos encuadernados, 1936. El subrayado aparece en el original. 
que él estaba por dejar al frente del Consejo de Ministros una vez que asumiera la primera magistratura del Estado ${ }^{38}$ - como la garantía para evitar la revolución, pero no lo presentaba como si necesitase el soporte de la derecha más moderada para sostenerse. Entre la postura primera de la Santa Sede y la del embajador mediaba la merma de escaños sufrida por las derechas durante el recuento final de votos y la comisión parlamentaria de actas. Para Zulueta, el Gobierno de los republicanos de izquierda no tenía necesidad de apoyo político de las derechas, pero no estaba de más que el miedo a la implantación del comunismo - con el que jugaba el embajador - serenase a la oposición. En cuanto a Azańa, el diplomático lo situaba como una figura casi taumatúrgica cuya sola presencia controlaría a las izquierdas revolucionarias manteniendo la democracia. El Gobierno del Frente Popular se presentaba a sí mismo con una posición de fortaleza en sus relaciones diplomáticas con la Santa Sede. Zulueta tenía instrucciones para "procurar dar la impresión» de que no llegaba a Roma con la intención de pactar ningún concordato ni acuerdo alguno de carácter general, aunque sí de plena disposición para estudiar cualquier problema, favorecer coincidencias y sostener unas relaciones serenas y con «espíritu conciliador ${ }^{39}$.

El 4 de mayo tuvo lugar el primer encuentro de Zulueta con el cardenal secretario de Estado. Aunque fue ocasión de volver sobre la cuestión de la amenaza comunista, Pacelli quiso abordar desde el comienzo de la misión de Zulueta la cuestión del orden público, si bien lo hizo «en tono dolido pero amistoso». El embajador le manifestó «cuán sinceramente el Gobierno lamentaba y con cuanto empeño se esforzaba en impedirlos [los ataques], esperando que no volvieran a ocurrir». Pero no se limitó el diplomático a decir a Pacelli lo que este quería oír, y lo que probablemente en un primer encuentro en aquellas circunstancias no había más remedio que decir, sino que le planteó un cuadro de la situación en el país en que parecía invitar a la propia Iglesia a una reflexión sobre su papel en España. El embajador señaló que los ataques se efectuaban a la vez a los templos y conventos y a los centros políticos «abiertamente hostiles a la República». Pacelli, con una calculada prudencia vestida de exquisita cortesía, no negó ni afirmó que los ataques estuvieran causados por la significación política del clero. Se limitó a remitirse a la llamada a la unidad que había hecho insistentemente el Papa y dijo que los obispos y sacerdotes no debían hacer política de partido, sino

38 Azaña asumió la Presidencia de la República, en sustitución del destituido Alcalá Zamora, el 11 de mayo de 1936.

39 Despacho núm. 114 al ministro de Estado, de 1 de mayo. AEESS, despachos encuadernados, 1936. 
solo aquella que tendía a los grandes intereses de «la moral, la familia, la educación y el bien común $»^{40}$.

Con todo, el punto principal de aquel encuentro estuvo en la petición que el Secretario de Estado hizo al novísimo embajador para que incluyera en el discurso de presentación de credenciales «alguna manifestación en el sentido de "mitigar" los efectos de la legislación laica de la República». A Zulueta debió resultarle demasiado atrevido el movimiento de su interlocutor. Aceptaba que el término «mitigar» podía albergar muchos matices y que probablemente podía ser objeto de negociaciones, pero en absoluto juzgaba prudente hacer una afirmación como la solicitada en el discurso de presentación de credenciales ante Pío XI. En cualquier caso, el embajador estaba firmemente convencido de que aquella "política de mitigación» volvería a surgir en la conversación.

Efectivamente, lo hizo pocos días después, cuando Pacelli le devolvió la visita de cortesía después del acto de entrega de credenciales. Este había tenido lugar el sábado 9 de mayo de 1936. En él aludió el papa a las «tribulaciones» de la Iglesia en España, de las que dijo que estaban siendo «sufridas no ciertamente por culpa nuestra», pero sin atribuir responsabilidad alguna a nadie ni referirse a ningún hecho concreto. En cualquier caso, la afirmación del pontífice establecía un límite a la actitud del embajador que había pretendido hacer pasar a la propia Iglesia como culpable de los ataques que sufría a causa de su posicionamiento político. Cuando Pacelli devolvió la visita, se hizo cargo de que en unas circunstancias como aquellas no era razonable aspirar más que a la «política de mitigación» en la interpretación o aplicación de las leyes ${ }^{41}$.

\section{ASPIRACIÓN Y PRÁCTICA DE UNA «POLITICA DE MITIGACIÓN»}

Mientras la Santa Sede atendía al temor de que España se convirtiese en un país comunista, debía entenderse a su vez con un Gobierno que se presentaba a sí mismo como dique para la contención de esta amenaza que efectuaban sus propios aliados en las urnas. La Iglesia inició el periodo ofreciendo el apoyo de sus fuerzas más afines en materia social a cambio de que se "mitigara» el programa antirreligioso, que no había sido cuestión central en la articulación del pacto electoral. Sin embargo, las izquierdas

40 Despacho núm. 116 al ministro de Estado, de 4 de mayo. AEESS, despachos encuadernados, 1936.

41 Despacho núm. 122 al ministro de Estado, de 11 de mayo. AEESS, despachos encuadernados, 1936. 
republicanas en el poder no aceptaron esta posibilidad confiando en su alianza con los socialistas ${ }^{42}$.

La primera de las medidas en tomarse fue la reactivación de la clausura de las escuelas católicas, en conformidad con el precepto constitucional que impedía a los religiosos el ejercicio de la enseñanza. Azaña había defendido durante los debates constitucionales que el cierre de los colegios religiosos era una cuestión de «defensa de la República»" ${ }^{43}$. Así, el Ministerio de Instrucción Pública y Bellas Ates que ostentaba Marcelino Domingo publicó una orden circular el 29 de febrero de 1936 dirigida a los inspectores jefes de Primera Enseñanza encareciéndoles a informar acerca de cuántos colegios atendidos por congregaciones religiosas podían ser sustituidos por escuelas nacionales, así como de aquellos pueblos en los que la sustitución no podía todavía realizarse $^{44}$. La labor que de antemano tenían que cumplir los inspectores se la arrogaron en muchos casos las autoridades locales que debían su poder a la reposición decretada por el Gobierno Azaña en favor de los ayuntamientos destituidos en el anterior bienio. Se dieron así la mano el cumplimiento de la legalidad con el apasionamiento político de las masas, que comenzaron a iniciar la clausura de los colegios sin mediar trámite administrativo alguno, sino consiguiendo la llave e incautándose del centro en muchos casos ${ }^{45}$. El fenómeno alcanzó tal dimensión que el Gobierno tuvo finalmente que sancionar las clausuras efectuadas y para el 20 de mayo se dispuso el cierre total de las escuelas religiosas so pretexto de evitar los ataques que estaban sufriendo ${ }^{46}$.

La sustitución de la enseñanza religiosa por la educación pública representaba un ámbito capital en el que aplicar aquello que Pacelli había llamado al recibir a Zulueta "política de mitigación». Y es que para puentear la prohibición legal de enseñanza a cargo de las congregaciones se había articulado un modelo que pasaba por erigir los colegios en escuelas privadas en las que podía formarse a los pequeños con criterios católicos y evitar el modelo laico de las escuelas nacionales. Estas escuelas privadas no podían estar afectadas por la legislación contra las congregaciones, puesto que no eran formalmente de titularidad religiosa. Si el Gobierno hubiera querido el entendimiento, hubiera aceptado la

\footnotetext{
Payne (2016): 92.

Lannon (1990): 219.

4 Gaceta de Madrid, núm. 60, 29-2-1936, p. 1703.

45 Rodríguez Lago (2013: 516) ha señalado cómo estas actuaciones provocaron la reacción católica contraria. Ostolaza Esnal (2009: 337) ha indicado, en una breve referencia al periodo, que «la nueva ofensiva de laicización escolar [...] truncaba toda posibilidad de acuerdo entre la Iglesia y el régimen republicano».

46 García Prous (1996): 211.
} 
existencia de este modelo educativo siquiera como vía de escape para la presión que la obra de sustitución de las escuelas religiosas suponía. Sin embargo, estas escuelas fueron objeto de la visceralidad de las autoridades locales para combatir las muestras de religiosidad. Se provocó así un conflicto diplomático entre el pronuncio ${ }^{47}$ Tedeschini y el ministro de Estado, Barcia, que afeó los últimos días del cardenal en la Nunciatura de Madrid. El 16 de mayo de 1936, Tedeschini dirigió una áspera y contundente nota verbal al ministro en la que pedía que cesaran «el abuso y el insidioso atropello que las escuelas privadas, a pesar de estar sometidas a la Constitución", estaban sufriendo por parte de las autoridades locales por el hecho de "darse en ellas enseñanza confesional católica». Pedía, además, que no se confundiese la enseñanza "congregacionista» con la enseñanza privada permitida por la Constitución, y por tanto «perfectamente legal, máxime cuando esta enseńanza privada se dé por personas dotadas del correspondiente título legal $»^{48}$.

Más allá de la trascendencia que el tono de la nota tuvo ${ }^{49}$, Tedeschini asumía el cumplimiento legal de la disposición que más debía incomodarle, pero apelaba a la falta de ortodoxia legal en los procedimientos por parte de las mismas autoridades del Estado. Es decir, dispuesto al sometimiento a una norma que no era grata, la protesta formal se dirigía a la falta de acatamiento de la legalidad de las propias autoridades que pretendían imponer este cumplimiento. El final de la nota no era más amigable. Y quizás neutralizaba en parte la impecable juridicidad de los puntos precedentes al indicar que «la Iglesia no podría nunca abandonar [la enseñanza] porque es de derecho natural y divino", conforme a la doctrina social de la Iglesia, aunque también

47 Se utiliza esta categoría para señalar al nuncio que no ejerce como decano del cuerpo diplomático. Fue la condición de Tedeschini al final de su nunciatura.

48 Copia de la nota verbal remitida por Tedeschini al cardenal Pacelli, en el Archivo de la Congregación de Asuntos Eclesiásticos Extraordinarios (en adelante AES), Spagna (IV), 886 p.o., fasc. 259, f. 23. La argumentación de Tedeschini contrasta con el mandato legal de cuidar que las órdenes y congregaciones no pudiesen sostener colegios de enseñanza privada ni por sí ni por medio de personas interpuestas. Suárez Pertierra (2001: 81).

49 El 23 de mayo de 1936 el subsecretario de Estado visitó a Tedeschini, convaleciente de ciática, para afearle el tono de las protestas dirigidas al Gobierno y que estas no hubieran estado remitidas exclusivamente al ministro de Estado. Al cardenal le molestó mucho la descortesía del Gobierno cuando estaba a punto de marcharse. Entendió que la molestia venía por su ausencia en la recepción de Azaña como nuevo presidente de la República al cuerpo diplomático. El eclesiástico adujo la convalecencia para no asistir y el Gobierno interpretó que se trataba de una excusa. Cárcel Ortí (2016): documento 1628. 
podría interpretarse aquel alegato final como una invitación a dejar algún resorte posible para que los católicos pudieran apelar a la propagación de la fe.

En relación también a la sustitución de la enseñanza religiosa se produjo otra circunstancia en la que podría haberse impuesto aquella «política de mitigación» que había sugerido Pacelli. El 22 de mayo de 1936 Tedeschini volvió a dirigirse a Barcia para indicarle que, «entre las muchas escuelas que se vienen clausurando", estaban también las de la hijas de la caridad tanto de la rama francesa como de la española, habiendo sido para esa fecha ya clausuradas las escuelas de Alcoy, Galdo y Reinosa y estando a punto de cerrarse las de Aibar, Sangüesa y Marín. Tedeschini apuntaba al respecto un matiz bastante revelador:

[...] esta clausura de Escuelas dirigidas por Hijas de la Caridad, aplicándoles el precepto prohibitivo del art. 26 de la Constitución y del art. 30 de la Ley de Confesiones y Congregaciones Religiosas, es absolutamente ilegal y contraria a resoluciones dadas por la autoridad competente, por la razón fundamental y clarísima de que el art. 22 de la mencionada Ley de Confesiones y Congregaciones Religiosas considera expresamente, y por cierto en conformidad con el Derecho Canónico, como Órdenes y Congregaciones Religiosas sólo a las Sociedades aprobadas por la Autoridad Eclesiástica y en las cuales sus miembros emiten votos públicos, perpetuos o temporales, y las Hijas de la Caridad de San Vicente de Paúl, por el contrario, emiten por virtud de sus Constituciones sólo votos privados anuales, y por consiguiente no son Religiosas, ni canónica, ni civilmente, según el artículo mencionado, a pesar de su hábito y de su vida en común, siendo el concepto canónico de esta Institución el de 'Sociedad de Señoras que viven en común sin votos (públicos) ${ }^{350}$.

En su nota de protesta el pronuncio explicaba además que en agosto de 1933 se había dirigido al presidente del Consejo de Ministros, entonces Azaña, encareciéndole a requerimiento de los directores de la institución religiosa que esta fuera considerada al margen tanto de la Ley de Congregaciones como del art. 26 de la Constitución. El Consejo de Estado suspendió cautelarmente la aplicación de esta legislación a las hijas de la caridad el 2 de septiembre de 1933 y a finales de marzo de 1934 los directores de la institución recibieron del Ministerio de Justicia dos decretos según los cuales las hijas de la caridad de San Vicente de Paúl no se incluían en la Ley de Congregaciones y, además, quedaban inscritas en el Ministerio de Justicia con existencia legal. El 10 de marzo de 1935 el Ministerio de Instrucción Pública publicó una orden en la

50 Copia de la nota enviada al ministro Barcia en AES, Spagna (IV), 886 p.o., fasc. 259, ff. 26-29. 
que contaba que «desde el momento en que ha sido declarado por quien tiene competencia para ello que su Instituto está excluido de la Ley de Confesiones y Congregaciones religiosas, pueden ejercer la enseñanza siempre que reúnan los requisitos que para ello exigen las vigentes disposiciones». Por todo ello, Tedeschini fue muy claro al invitar al Gobierno de la República a cumplir las disposiciones emanadas de su propia autoridad.

El tratamiento que de la cuestión hizo la Nunciatura deja ver que, en este sentido, la actitud de esta estaba mucho más plegada a la legalidad republicana que la de algunas autoridades del país. Por ello, la representación de la Santa Sede reclamaba el cumplimiento de la legalidad en este ámbito en el que resultaba beneficioso para los intereses de la Iglesia. Sin embargo, esta adecuación a la modernidad de los que más encarnaban la oposición a las innovaciones no era solo un fenómeno de la representación diplomática. Rafael Cruz ha señalado que los católicos respondieron orquestando un movimiento social que «consistió en un despliegue de asociaciones, recogidas de firmas, envío de escritos, manifiestos, mítines, algún boicot, colectas, manifiestos, congresos y asambleas, con el apoyo de la prensa $w^{51}$. El 5 de julio de 1936 le fue remitida a la Secretaría de Estado la información referente a la espontánea campaña de protesta de las mujeres de los barrios populares de Madrid contra la clausura de los colegios católicos, que perjudicaba a las "familias más humildes». La información aludía a la recogida de casi setenta mil firmas de estas mujeres. Silvio Sericano, como encargado de Negocios a la marcha de Tedeschini, advertía de la escasa influencia de la iniciativa en el Gobierno, pero lo remitía como muestra de la religiosidad de aquella población; y de su capacidad para orquestar modos democráticos para canalizar su protesta ${ }^{52}$.

La política de «no mitigación» por la que finalmente optó el Gobierno no se circunscribió solo a la sustitución de la enseñanza que estaba en manos de las congregaciones religiosas, el 28 de junio una orden del Ministerio de Trabajo vino a derogar una disposición anterior de diciembre de 1934 que permitía que en los centros de beneficencia general del Estado se celebraran los cultos religiosos solicitados por los acogidos y ordenar su sostenimiento con cargo a las consignaciones para la subsistencia de los mismos. La nueva orden prohibía la celebración de culto alguno en estos centros y también su financiación, aunque permitía la posibilidad de que los interesados pudieran salir para acudir a los actos de culto en la medida en que el reglamento de cada institución lo posibilitara ${ }^{53}$.

51 Cruz (2006): 127.

52 AES, Spagna (IV), 886 p.o., fasc. 259, f. 49.

53 Gaceta de Madrid, 28-6-1936, núm. 180, p. 2733. 
El entonces encargado de Negocios de la Santa Sede, Sericano, se dirigió de nuevo a Barcia para protestar por la medida, dejándonos también una muestra de un amplio dominio de la legislación republicana y de una fina sutileza a la hora de utilizar los medios del ordenamiento jurídico para la defensa de los intereses de la Iglesia. Expuso que, a su criterio, la disposición restringía la libertad de conciencia que consagraba la Constitución:

El laicismo del Estado podrá tener como consecuencia lógica que aquel no establezca ni menos imponga por su iniciativa la celebración de estos actos [...]; pero no se ve por qué razón en virtud del laicismo, se debe hacer imposible a los ciudadanos acogidos por necesidad a los establecimientos del Estado la asistencia dentro de los mismos a los cultos, que forman parte integrante y esencial de libre práctica de la religión [...] Además la Orden citada interpreta en sentido restrictivo y peyorativo las disposiciones del art. $4 .^{\circ} \mathrm{de}$ la Ley de Confesiones y Congregaciones Religiosas; pues además de conservar la cláusula 'cuando la ocasión lo justifique', tan expuesta a abusivas interpretaciones, mientras el referido artículo habla de prestación de servicios religiosos en general, dentro de las dependencias, la Orden los restringe a los de naturaleza individual ${ }^{54}$.

El 2 de julio de 1936 fue el Ministerio de Marina quien ordenó la sustitución de las hijas de la caridad que prestaban su servicio de asistencia en los hospitales de la Armada ${ }^{55}$. El encargado de Negocios volvió a formular una protesta en forma de nota verbal llamando la atención sobre la redacción del art. 5 del texto dispositivo,

en el que se dispone que "todo el personal civil que preste servicio en lo sucesivo en los hospitales de Marina no podrá ser confesional»; pues si se da a la palabra confesional el sentido corriente de perteneciente a una confesión religiosa, el artículo mencionado vulnera abiertamente el Art. 27 de la Constitución que además de consignar que «la libertad de conciencia y derecho de profesar y practicar libremente cualquier religión quedan garantizados en el territorio español», declara que «la condición religiosa no constituirá circunstancia modificativa de la personalidad civil ni política», y aun si se quiere dar a esa palabra el sentido impropio de adscrito a una Congregación Religiosa, aún entonces, al menos tratándose de individuos, se infringe el mismo precepto constitucional, ya que solo para los cargos de Presidente de la República y de Presidente del

54 ASV, Nunziatura de Madrid, b.966, ff. 176r-177r.

55 Gaceta de Madrid, 2-7-1936, núm. 184, p. 38. 
Consejo, puede ser obstáculo legal, segun [sic] los artículos 70 y 87 de la Constitución, la profesión religiosa ${ }^{56}$.

Alejándose del tono áspero que había provocado a Tedeschini el roce con el Gobierno, Sericano fue bastante hábil al presentar a Barcia la nota verbal con el objeto de que el Gobierno «se sirva aclarar el mencionado artículo 5. ${ }^{\circ}$ en sentido que evite interpretaciones no ajustadas a la Ley Fundamental de la República por parte de los encargados de aplicarlo».

Tras la marcha de Tedeschini el 11 de junio de 1936, correspondió a Sericano completar la serie de protestas por los ataques sufridos por la Iglesia en todo el país que había venido presentando el nuncio desde poco después de las elecciones. Con la documentación enviada por cada una de las diócesis se preparó un extenso informe sobre los «desmanes antirreligiosos» cometidos en las diócesis españolas entre el 1 de abril y el 20 de junio que arrojaba la cifra de 836 sucesos, de muy diferente gravedad. Fue presentado al ministro de Estado por Silvio Sericano a comienzos de julio ${ }^{57}$.

La labor del encargado de Negocios en relación con los «desmanes» cometidos contra la Iglesia no se limitó a llevar a término el informe completo de todas las diócesis iniciado por Tedeschini, sino que en la Nunciatura en manos de aquel recién llegado se produjo un giro copernicano en el tratamiento de la información que merece ser muy tenido en cuenta a la hora de valorar la adecuación de la Iglesia a los resortes del derecho en una situación tan delicada como aquella. Ya en la presentación de los datos que había mandado recoger Tedeschini advirtió que en muchos pueblos estaba impedida «toda vida religiosa y todo ejercicio del culto, por motivos desprovistos de todo fundamento legal, con evidente quebranto de la libertad religiosa " ${ }^{58}$. Era la consecuencia de que arbitrariamente las fuerzas locales partidarias de la coalición de izquierdas, que ostentaban en muchos casos la autoridad local, hubieran incautado la iglesia y otros edificios religiosos y hubieran impedido

56 ASV, Nunziatura de Madrid, b. 967, ff. 493r-494r.

57 El informe aparece transcrito literalmente en Cárcel Ortí (2008): 698-733. El número es comparativamente muy alto respecto al total de 957 ataques que contabilizaron Tardío y Villa y que citamos anteriormente. Ello se debe a que estos autores aclararon que no contabilizaron «los episodios de amenazas y coacciones [...] tampoco [...] las huidas o expulsiones de clérigos, las multas, las detenciones y los registros e incautaciones de edificios». El informe enviado por Sericano incluye esta amplia gama de «desmanes» que refería situaciones de anormalidad. Especialmente debe considerarse en esta categoría la clausura de colegios por parte de las autoridades locales.

58 ASV, Nunziatura de Madrid, b. 967, f. 64. 
al sacerdote el ejercicio de su ministerio, expulsándole del pueblo en muchos $\operatorname{casos}^{59}$. A partir de ello, fue en la primera quincena de julio cuando efectuó un informe relativo a las poblaciones españolas que estaban sin asistencia religiosa. La idea, que pudo tomar de una iniciativa en las Cortes de la derecha regional valenciana ${ }^{60}$, era orientar el sentido de la protesta no hacia el Ministerio de Gobernación sino al de Justicia. Era el resultado de todos los esfuerzos invertidos en denunciar los «desmanes» contra la Iglesia sin que las fuerzas de seguridad consiguieran impedir que se reprodujeran, por lo que había ya cumplida muestra de que no iba a ser el Ministerio de Gobernación el que pusiera remedio a la situación ${ }^{61}$.

Sericano envió una circular a los obispos el 29 de junio de 1936 pidiendo la información sobre las parroquias desprovistas de asistencia religiosa y su causa. El 15 de julio, Sericano dejó listo —aunque no llegó a presentar ${ }^{62}$ - el resultado de su encuesta: en un total de veintiuna diócesis españolas ${ }^{63}$ había parroquias sin asistencia religiosa a causa de los ataques, siendo muchas de las afectadas las únicas que había en poblaciones pequeñas. El total de población afectada la estimaba Sericano en 654766 personas repartidas en las diócesis de Astorga, Badajoz, Cartagena, Ciudad Real, Granada, Guadix-Baza, Jaén, Lérida, Madrid-Alcalá, Málaga, Mondoñedo, Orense, Orihuela, Palencia, Santiago de Compostela, Segorbe, Sevilla, Teruel, Toledo, Valencia y Zaragoza. Entre todas ellas destacaban las diócesis de Valencia y de Cartagena, que además de ser próximas entre sí, superaban en ambos casos las cien mil personas afectadas. Solo la diócesis de Valencia contenía el 31,25\% de la población afectada, representando la de Cartagena el 20,28\%. Contigua también a ambas se presentaba la diócesis de Orihuela con 59586 personas afectadas, de forma que estas diócesis levantinas representaban el 60,63\% del total de la población contenida en el informe ${ }^{64}$.

59 En este sentido, es preciso matizar que en algunos pueblos se había impedido el ejercicio de la cura de almas al párroco del lugar, pero no a otros sacerdotes llegados de fuera del municipio.

60 El 18 de junio de 1936, Sericano informó a Pacelli de la moción en favor de la asistencia religiosa en Valencia. AES, Spagna IV, p.o. 881, fasc. 257, f. 8.

61 Álvarez y Villa (2013): 706-720. Los autores han estudiado la respuesta de las autoridades a los ataques documentando muchos casos en que esta fue «tibia y tardía»; sin embargo, «el análisis general revela un comportamiento ambivalente y poliédrico por parte de las autoridades».

62 Minuta de la nota de presentación en ASV, Nunziatura de Madrid, b. 967, f. 240r-241r.

63 En otras treinta no se daba esta circunstancia. Del resto no se presentaron datos.

64 El informe por diócesis en ASV, Nunziatura di Madrid, b. 967, ff. 278-297. 
Los datos, no obstante, deben ser tomados con dos cautelas fundamentales. La primera es que la estimación de población la aportaban los propios prelados, por lo que no tiene base más que estimativa. La segunda es que en la mayoría de los casos se refieren a poblaciones completas. Esto es, suponiendo el total de una feligresía o población como almas que demandaban esta asistencia religiosa, cuando es fácil suponer que no todas las personas que vivían en una demarcación religiosa concreta precisaban de esta asistencia espiritual. Cuando menos, no querían que les atendiese ningún sacerdote aquellos que habían expulsado a los eclesiásticos.

\section{CONCLUSIONES}

La permanente duda de muchos católicos sobre si el deterioro del orden público conduciría o no al establecimiento del comunismo marcó la primavera de 1936. No fue ello óbice para que la Santa Sede tratase de atraer hacia el centro político a las izquierdas republicanas como medio para evitar los excesos de sus socios de coalición y la revolución a la que estos aspiraban. En esta estrategia, el Gobierno romano de la Iglesia dejó ver su malestar por lo que juzgaba una política social débil por parte de la CEDA durante el segundo bienio, como también se dolía de la incapacidad de los católicos españoles de apartar sus divisiones políticas en favor de una acción común.

Las orientaciones de la Santa Sede, con ser políticamente consecuentes con los principios religiosos que las inspiraban, adolecieron en algunos casos de una cierta candidez. Fue así al tratar de desmovilizar a los monárquicos en los momentos de mayor debilidad de la República, cuando más fácil podrían tener la conquista de sus anhelos. Pudo serlo también cuando censuró la debilidad de política social de la CEDA evidenciada en la caída de Giménez Fernández. Su sustitución en Agricultura fue, en buena medida, un medio para mantener la unidad del amplio bloque posibilista que amenazaba con resquebrajarse si se continuaba enfrentando a los intereses de sus propios integrantes. Estos reproches, sin embargo, contrastan con los éxitos obtenidos por la CEDA en la movilización social de los católicos, cuyos resultados electorales en 1936 - aun no consiguiendo la mayoría - fueron todo un éxito visible en los primeros datos del escrutinio.

La estrategia de la Santa Sede de intentar atraer al centro a los republicanos de izquierda no obtuvo los efectos deseados. Fue así desde luego en cuanto al control de los ataques sufridos por la Iglesia. Las fuentes insisten en que el Gobierno no pudo o no quiso actuar contra las fuerzas revolucionarias que se integraban en el Frente Popular con la contundencia que exigía el respeto a la 
legalidad. También fracasó la «política de mitigación» en materia religiosa pretendida por la Secretaría de Estado a cambio del apoyo a las medidas legislativas de carácter social. El Gobierno no solo no quiso comprometerse a ello, sino que continuó desarrollando su hostilidad hacia lo católico en nuevas reglamentaciones que a veces contravinieron disposiciones legales superiores. La aplicación de algunas de estas medidas por las autoridades locales provisionales supuso muchas veces un agravante. Con todo, las orientaciones de la Santa Sede se mantuvieron en el preciso conocimiento de la legalidad y el plegamiento a lo dispuesto en ella, intentando salvar mediante lo dispuesto en el ordenamiento jurídico los intereses que fueran posibles.

\section{Bibliografía}

Alcalá Zamora, N. (1998). Memorias. Barcelona: Planeta.

Álvarez Rey, L. (2005). La relación entre Giménez Fernández y Gil Robles y la división de la democracia cristiana durante el franquismo. En J. M. Castells, J. Hurtado y J. M. Margenat (eds.). De la dictadura a la democracia (pp. 205-221). Sevilla: Desclée de Brouwer.

Álvarez Tardío, M. (2016). Gil-Robles, un conservador en la República. Madrid: Gota a Gota; Fundación FAES.

Álvarez Tardío, M. y Villa García, R. (2013). El impacto de la violencia anticlerical en la primavera de 1936 y la respuesta de las autoridades. Hispania Sacra, 132, 683-764. Disponible en: https://doi.org/10.3989/hs.2013.033.

- (2017). 1936: Fraude y violencia en las elecciones del Frente Popular. Barcelona: Espasa.

Batllori, M. y Arbeloa, V. M. (1990). Arxiu Vidal y Barraquer. Església i estat durant la Segona República Espanyola, 1936-1936 (vol. 4, parte 3). Barcelona: Monestir de Monstserrat.

Cárcel Ortí, V. (2008). Pío XI entre la República y Franco. Madrid: Biblioteca de Autores Cristianos.

- (2016). La II República y la Guerra Civil en el Archivo Secreto Vaticano (vol. 4; años 1935 y 1936). Madrid: Biblioteca de Autores Cristianos.

Cruz, R. (2006). En el nombre del pueblo. República, rebelión y guerra en la España de 1936. Madrid: Siglo XxI.

De la Cueva Merino, J. (1998). El anticlericalismo en la Segunda República y la Guerra Civil. En E. La Parra López y M. Suárez Cortina (eds.). El anticlericalismo español contemporáneo. Madrid: Biblioteca Nueva.

Delgado Ruiz, M. (2001). Luces iconoclastas. Anticlericalismo, espacio y ritual en la España contemporánea. Barcelona: Ariel.

Elorza, A. y Bizcarrondo, M. (1999). Queridos camaradas: la Internacional Comunista y España 1919-1939. Barcelona: Planeta.

García Prous, C. (1996). Relaciones Iglesia-Estado en la Segunda República Española. Córdoba: Publicaciones Cajasur.

González Calleja, E. (2014). En nombre de la autoridad. La defensa del orden público durante la Segunda República española (1931-1936). Granada: Comares. 
González Gullón, J. L. y Martínez Sánchez, S. (2017). Los temblores del clero durante el Frente Popular. En Actas del XIII Congreso de la Asociación de Historia Contemporánea (Albacete, 21-23 de septiembre de 2016): La Historia, lost in translation? (pp. 1615-1625). Cuenca: Universidad de Castilla-La Mancha.

Lannon, F. (1990). Privilegio, persecución y profecía. La Iglesia Católica en España 1875-1975. Madrid: Alianza Universidad.

Macarro Vera, J. M. (2000). Socialismo, República y revolución en Andalucía (1931-1936). Sevilla: Secretariado de Publicaciones de la Universidad de Sevilla.

Navarro de la Fuente, S. (2017). El Frente Popular, ¿̨un dique contra la revolución o el primer paso de la misma? Miedos y cautelas de la Iglesia Católica. En Actas del XIII Congreso de la Asociación de Historia Contemporánea (Albacete, 21-23 de septiembre de 2016): La Historia, lost in translation? (pp. 1661-1672). Cuenca: Universidad de Castilla-La Mancha.

Ostolaza Esnal, M. (2009). La "guerra escolar» y la movilización de los católicos en la II República. En J. De la Cueva y F. Montero (eds.). Laicismo y catolicismo. El conflicto político-religioso en la Segunda República (pp. 321-350). Madrid: Universidad de Alcalá de Henares.

Payne, S. (2016). El camino al 18 de julio. La erosión de la democracia en España (diciembre de 1935-julio de 1936). Barcelona: Espasa.

Raguer, H. (2001). La pólvora y el incienso. La Iglesia y la Guerra Civil española (1936-1939). Barcelona: Ediciones Península.

Ranzato, G. (2011). La grande paura del 1936. Come la Spagna precipitò nella guerra civile. Bari: Larteza.

Redondo Torres, G. (1993). Historia de la Iglesia en España 1931-1939. Madrid: Rialp.

Rees, T. (2012). ¿Revolución o República? El Partido Comunista de Espańa, 1931-1936. En M. Álvarez Tardío y F. Del Rey (eds.). El laberinto republicano. La democracia española y sus enemigos (1931-1936) (pp. 281-305). Barcelona: RBA.

Rodríguez Lago, J. R. (2013). El acoso de las Repúblicas. Las congregaciones religiosas y los procesos de construcción nacional en Galicia (1898-1936). En P. Gabriel, J. Pomés y F. Férnandez Gómez (eds.). España Res publica. Granada: Comares.

- (2017). Las claves de Tedeschini. La política vaticana en España (1921-1936). Historia y Política, 38, 229-258. Disponible en: https://doi.org/10.18042/hp.38.08.

Suárez Pertierra, G. (2001). El laicismo de la Constitución republicana. En D. Llamazares Fernández (ed.). Estado y Religión. Procesos de secularización y laicidad. Homenaje a Don Fernando de los Ríos. Madrid: Universidad Carlos III; BOE.

Thomas, M. (2014). La fe y la furia. Violencia anticlerical popular e iconoclastia en España, 1931-1936. Granada: Comares. 